\section{Sociología de la solidaridad. La diferenciación de un sistema global de cooperación}

\author{
Aldo Mascareño*
}

\section{Palabras clave}

Diferenciación funcional, medio de comunicación simbólicamente generalizado, acoplamiento estructural, colaboración, solidaridad

* Doctor en Sociología Universidad de Bielefeld, Alemania. Académico Departamento de Ciencias Sociales Universidad Alberto Hurtado. amascaren@uahurtado.cl
Resumen. La diferenciación funcional es un proceso de carácter contingente. Esto supone que constelaciones sistémicas existentes pueden descomponerse o que otras nuevas pueden surgir. Un sistema de la cooperación parece haber alcanzado un umbral de emergencia en el siglo XX, aunque no autopoiesis. Su función es la transformación de la exclusión en inclusión a través de distintas organizaciones acopladas al sistema, que operan sobre la base del medio de comunicación simbólicamente generalizado colaboración. La solidaridad opera como fórmula de contingencia del sistema, lo que posibilita el desarrollo creciente de densos acoplamientos estructurales. 


\section{Diferenciación de la sociedad}

El proceso de diferenciación funcional que caracteriza a la sociedad moderna supone el desarrollo evolutivo de estructuras especializadas en la resolución de problemas sociales crecientemente generalizados que surgen del mismo proceso de diferenciación. Constelaciones problemáticas que en el contexto de la sociedad estratificada eran resueltos independientemente por las condiciones de organización de cada rango y por la subordinación decisional al estrato superior, son tratadas en la sociedad moderna por una estructura social y una semántica que se diferencia y especializa evolutivamente en el procesamiento y orientación de los diversos complejos institucionales y de sentido que caracterizan el ordenamiento social contemporáneo. La sociología sistémica (Luhmann, Willke, Stichweh, Teubner) denomina a estas instancias sistemas funcionales.

La evolución de los sistemas funcionales es de carácter incremental, acontece en largos períodos de tiempo y sólo puede ser reconstruida retrospectivamente. Para la emergencia del sistema económico en el sentido moderno, por ejemplo, es necesaria la diferenciación semántica del dinero como medio de intercambio y, por cierto, el desarrollo de estructuras jurídicas que faciliten las transacciones y aseguren las expectativas de aquellos que optan por el dinero ( $y$ no por el trueque o algún tipo de intercambio ritual) como medio de realización de la actividad económica. Paralelamente es necesario que tal forma de resolver las cuestiones económicas no quede restringida a un territorio específico, sino que se expanda vía contacto (colonización, imperialismo, evangelización, guerras, relaciones de frontera) hacia nuevos espacios geográficos en los cuales se forman las estructuras y se consolidan las semánticas asociadas al procesamiento de los problemas económicos vía el medio dinero.

Lo que sucede para la economía puede observarse también para la política, el sistema jurídico, la religión, la ciencia, la educación, las relaciones íntimas o el arte de la sociedad, sistemas que configuran la imagen actual de la sociedad moderna de tipo mundial como un orden policéntrico (Willke 1987). La existencia de estos sistemas, sin embargo, no debe entenderse de modo determinista ni finalista. La evolución es producción de contingencia desde estructuras estabilizadas. Que la sociedad evolucione significa que ella permanentemente cambia; en otras palabras, significa que tendencias de desdiferenciación y diferenciación sistémica pueden presionar por la integración de estructuras y semánticas que antes estuvieron diferenciadas o por la diferenciación de otras que comienzan a alcanzar un alto nivel de especialización en el contexto de constelaciones mayores como la propia economía, la religión o el sistema jurídico. Tal es el caso de lo que en este texto queremos entender como la diferenciación de un sistema global de cooperación. 
Por diferenciación de la cooperación se debe entender el proceso evolutivo de constitución de un nuevo sistema social en el contexto de la sociedad funcionalmente diferenciada moderna concebida como sociedad mundial, es decir, como sociedad en la que los sistemas que la conforman muestran consecuencias tanto estructurales como semánticas para cada rincón geográfico del globo (II). En el caso del sistema de la cooperación estas consecuencias se expresan en su función de transformación de la exclusión en inclusión y se materializan en sus organizaciones, lo que sin embargo no permite hablar de un sistema autopoiético de la cooperación (III), no obstante determinadas condiciones estructurales y semánticas motivan socialmente a ello (IV). A pesar de tratarse de un sistema autoorganizado y autorregulado aunque no autopoiético, el sistema de la cooperación ha logrado decantar un medio de comunicación simbólicamente generalizado (V), el medio de la colaboración (VI), una suficientemente abstracta fórmula de contingencia como la solidaridad (VII) y acoplamientos estructurales crecientemente densos en especial con el sistema económico, político y jurídico, que pueden orientar al sistema en el siglo XXI hacia rendimientos autopoiéticos (VIII).

\section{Diferenciación de la cooperación como sistema}

La sociedad moderna sólo puede ser descrita correctamente como una sociedad mundial. Sociedad mundial supone una comprensión desterritorializada de lo social como comunicación, en tanto integra cada uno de los posibles horizontes de mundo — sea de individuos o colectivos - como horizontes de un único sistema comunicativo universal en el que se incluyen todas las posibilidades de comunicación (Luhmann 1990a, Stichweh 2000). En otros términos, no hay comunicación más allá de la sociedad mundial.

Que la sociedad sea entendida como comunicación en sólo un mundo, no significa homegeneidad de la comunicación en un sentido mundial. En el proceso evolutivo de la formación de las sociedades modernas, la comunicación se diferencia y constituye sistemas funcionales orientados a resolver problemas específicos de esas sociedades que emergen de su mismo proceso evolutivo. A esto remite el carácter policéntrico de la sociedad mundial.

Un principio de orden policéntrico está caracterizado por la dinámica centrífuga de la diferenciación funcional. Tales órdenes "no pueden ser ya más orientados desde un centro o desde una cima jerárquica. Son ahora sociedades policéntricas, en las cuales los sistemas parciales diferenciados representan, unos para otros, entornos sociales internos" (Willke 1987:3). La organización de las sociedades policéntricas se caracteriza por la disponibilidad de una lógica operativa propia a 
cada sistema, la que se logra evolutivamente por medio de una clausura operativa autorreferencial de códigos comunicativos específicos. A causa de esa clausura, los sistemas ganan en indiferencia frente al entorno, y producto de tal indiferencia se hacen necesarios mecanismos de coordinación que promuevan la interdependencia. Como consecuencia de ello, una representación jerárquica de la sociedad con un sistema omniabarcador que dé cuenta de su integración general, sea la religión, la moral, la política, pierde toda validez como descripción de la modernidad.

Cada una de las esferas en las que la sociedad se ha diferenciado produce rendimientos integrativos para sí mismas y condiciones de coordinación social verificadas por mecanismos de acoplamiento estructural, los que permiten la interrelación sistémica mediante la coutilización de la complejidad de diversas esferas — por ejemplo, entre derecho y política a través de la Constitución, entre economía y medios de comunicación a través de la publicidad, entre derecho y economía por medio del contrato (Luhmann 1997a). Los órdenes policéntricos acentúan la desigualdad y la interdependencia entre sistemas. Esto conduce a "la creciente formación de racionalidades parciales, objetivos subsistémicos contradictorios, formas diversas de construcción moral, diferencias internas específicas y diversos medios de orientación" (Willke 1996a:201). Así, los problemas de coordinación en las sociedades diferenciadas pueden ser comprendidos como consecuencia de la clausura operativa de los diversos centros que la constituyen.

Bajo estas consideraciones, la diferenciación de un sistema global de la cooperación, como aquí le queremos denominar, no puede comprenderse desde el punto de vista general de la mantención de la integración de la sociedad como un todo, es decir, no puede comprenderse desde la perspectiva del concepto decimonónico de solidaridad como unidad moral de la sociedad. El problema específico que debe resolver un sistema de la cooperación no es la mantención de la unidad (que se justifica moralmente) ante el riesgo de la diferenciación e individuación que caracteriza a las sociedades modernas. Esta es la forma clásica en que la sociología trató este tema en una línea que va de Comte, sigue con Durkheim, Tönnies, se especifica más modernamente con Parsons (Stichweh 2004) y se transforma actualmente en pilar de la filosofía política de orientación racionalista con Rawls.

Para las visiones decimonónicas, se requería un punto de anclaje que sustituyera la integración normativa que se derivaba de los criterios de validez de origen sacro en la sociedad estratificada. Comte entendió el Estado como el articulador de esa integración en la unidad de la diferencia orden/progreso (Bock 2001), Durkheim y Tönnies vieron más bien en las asociaciones de mediana escala la fuente de integración (Durkheim 1985, Tönnies 1991). Parsons (1966), en tanto, situó la integración en una perspectiva moral amplia que operacionalizó en su quinta variable-pauta: orientación al sí mismo vs. orientación al colectivo y, más contemporáneamente, 
Rawls (2002) entendió la cooperación como el rasgo distintivo básico de lo que denomina una sociedad bien ordenada de individuos libres e iguales.

Para la diferenciación de un sistema de la cooperación una amplitud funcional como la descrita en esta tradición es impracticable. Ningún sistema puede especificarse desde la función de integración normativa, precisamente porque por efectos de la diferenciación cada sistema diferencia sus propios criterios de inclusión y exclusión respecto del entorno. Para la sociedad como un todo, la única posibilidad de descripción unitaria que permanece es la de unidad de la diferencia o, puesto en otros términos, contingencia. Si la contingencia puede entenderse o no bajo la forma de un criterio normativo, es decir en tanto metanorma, es una cuestión discutible (Mascareño 2006), pero si esa metanorma ha logrado sedimentarse en las sociedades modernas, ella pudiera ser descrita como la expectativa de operar con normatividades diferenciadas para lograr una unidad en la que la selectividad de alter aparezca coordinada con la de ego. Un sistema encargado de realizar esta función sería un metasistema al interior de la sociedad o un mundo de la vida conceptualizado funcionalmente, es decir, como sistema social.

Cuando la evolución de la sociedad se ha encargado de problemas similares, ha tenido que especificar de tal manera el problema de referencia de la función que lo que resulta es un sistema funcional con un modo de autorregulación particular que también incluye lo que incluye y excluye lo demás. El sistema jurídico, en términos amplios, tiene por función el aseguramiento de las expectativas normativas en sociedades modernas (Luhmann 1997b). La moral, por cierto, también cumple una función similar, pero como Habermas indica, "en las sociedades complejas la moral sólo puede tener efectividad allende lo próximo si queda traducida al código jurídico o código con que funciona el derecho" (2000:175). Es decir, si evolutiva o históricamente se sedimentan determinados valores morales que una constelación social juzga apropiado asegurar en términos jurídicos, el derecho sólo los aceptará como jurídicamente relevantes en la medida en que esos valores hayan sido traducidos en norma jurídica por un procedimiento también jurídicamente establecido. Es decir, al derecho no le interesa la moral, sino la norma jurídica. Si una norma de tipo moral, como la preferencia de la integración por sobre la desintegración social, no ha sido codificada jurídicamente, el derecho no opera, no puede operar con ella. Ciertamente, puede integrarla como elemento de la argumentación jurídica, pero para ello debe haber previamente una decisión jurídica que se sustente en una norma de derecho positivo (Luhmann 1997b). El derecho moral a la igualdad de oportunidades, por ejemplo, ha de ser codificado jurídicamente para cada sistema en particular si se quiere hacer jurídicamente exigible en casos diversos: igualdad en el trabajo y no discriminación por edad o por género; igualdad en el acceso a la salud y la educación a pesar de las diferencias de nivel socioeconómico; igualdad en 
la familia frente a las cargas diferenciadas de roles; igualdad en el acceso al propio sistema jurídico por diferencias territoriales, de información o recursos.

Por tanto, la diferenciación de un sistema de la cooperación no podrá estructurarse bajo la semántica de la integración total de la sociedad; ello permanecerá en el plano de las expectativas morales de quienes tengan esa expectativa. Pero parece ser que en el contexto de las sociedades modernas hay un espacio específico que ha comenzado a ser ocupado por cierto tipo de relaciones en las que las condiciones de exclusión son transformadas en inclusión por la vía de rendimientos particulares que alcanzan altos niveles de autoorganización y autorregulación, aunque aún no de clausura operativa o autopoiesis. Al tipo de selectividad social que hace de la exclusión su problema particular de referencia es a lo que en estas páginas queremos denominar sistema de la cooperación social.

\section{Función y organización}

Un sistema de la cooperación social es un sistema en proceso de diferenciación. En esto empleamos la idea de temporalización de la autorreferencia de Teubner (1993), que en términos simples indica cuatro momentos de la evolución de un sistema: (a) autoobservación, (b) autoorganización y autorregulación, (c) autoproducción y (d) autopoiesis. La autoobservación permite la identificación de una unidad que tiene la pretensión de operar como tal; la autoorganización es la habilidad del sistema para producir un determinado orden; en tanto, la autorregulación es su dimensión dinámica, es decir, la capacidad para cambiar ese orden. La autoproducción es el desarrollo de comunicación específica del sistema socialmente generalizable y la autopoiesis es la capacidad del sistema de mantenerse a sí mismo como un todo en el tiempo.

Un sistema de la cooperación no es todavía un sistema autopoiético. En primera instancia, no logra una autoidentificación que lo diferencie sin ambigüedad de su entorno, aun cuando a nivel organizacional y de autorregulación hay una amplia gama de organizaciones orientadas a temas de exclusión: organizaciones de voluntariado; de cooperación internacional; de ayuda al desarrollo; de caridad y solidaridad; de ayuda en salud, educación, vivienda; de lucha contra la discriminación en distintos espacios o de superación de la pobreza incluso como organizaciones de autoayuda. Por otro lado, la amplia variedad de operaciones que pueden observarse bajo la perspectiva de la exclusión es también un obstáculo factual para la integración bajo una estructura unitaria de la autoproducción del sistema. Para lograr aquello únicamente sirve la evolución. Sin embargo, todo proceso de diferenciación sistémico se inicia de modo análogo a este. En la ciencia, sólo la proliferación de múltiples 
universidades con intereses diferenciados permitió la constitución de un sistema científico mundial; en la política, la multiplicación de los Estados es el antecedente para la universalización de estructuras políticas homólogas en diversos territorios; la universalización de la economía no pudo tener lugar sin la propagación de la organización empresarial a nivel mundial, y en la religión ninguna globalización de las creencias habría sido posible sin la dispersión de Iglesias alrededor del globo. La propagación de organizaciones orientadas a resolver problemas de exclusión puede ser vista entonces como un paso evolutivo importante en la diferenciación del sistema de la cooperación, como la formación del segundo momento de temporalización de la autorreferencia sistémica en el esquema más arriba descrito.

Los procesos evolutivos de la formación de sistemas no son actos voluntaristas de los miembros de las organizaciones que se acoplan a esos sistemas (Rodríguez 2004). Por ello, organizaciones dedicadas a temáticas muy particulares y locales tienen pocas probabilidades de formación evolutiva de sistemas. Organizaciones enfocadas en la reproducción de tradiciones, en el mejoramiento de barrios, en la conservación de alguna especie natural en particular, no responden en términos amplios a intereses generalizables que orienten la selectividad social en un sentido específico. Para el desarrollo de una función sistémica se requiere de problemas con una doble cualidad: alta abstracción, de modo tal que todos puedan verse afectados por ese problema, y alta especificidad, de modo tal que la resolución del problema sea abordada por mecanismos específicos y aquel pueda ser reconocido por observadores situados en distintas posiciones.

Las distintas organizaciones que parecen coordinarse en el marco de la diferenciación de un sistema de la cooperación, tienen como problema central de referencia la exclusión social. Esto comienza a otorgarle al sistema una función específica que lo constituye como sistema. En el contexto de una sociedad estratificada, la exclusión social viene legitimada por una semántica justificatoria primero sacra y luego natural del orden social (Friedrich 2004). Cada individuo está sujeto a la adscripción que resulta de su posición en la jerarquía y cualquier disidencia sólo puede entenderse como un movimiento contrario a la unidad del mundo. La pérdida del fundamento metafísico del orden social, que tiene su correlato estructural en la diferenciación sistémica, transforma la exclusión en un problema: no hay razones justificatorias transversales para la aceptación de la exclusión. Más aun: el desarrollo de la semántica de los derechos humanos en el siglo XX introdujo la consideración a nivel moral de la exigibilidad de la inclusión en distintos ámbitos. Por otro lado, diversos impulsos sistémicos mueven a la exigencia de inclusiones cruzadas para aceptar la participación de personas en sus rendimientos. El sistema de salud requiere pagos por sus rendimientos, lo que fomenta la exigencia de inclusión económica; algo similar sucede con el sistema educativo. El sistema científico 
exige una alta especialización en sus miembros, lo que supone como prerrequisito la inclusión en el sistema educativo; las decisiones colectivas vinculantes del sistema político adquieren fuerza de generalización en un Estado de derecho, es decir, por la inclusión jurídica de sus miembros; en tanto, el aseguramiento de la relación familiar, más allá del afecto mutuo que puedan (o no) tener los cónyuges, promueve la inclusión en relaciones jurídicas y también (aunque no siempre) religiosas en el marco del matrimonio. Por ello, cuando tiene lugar la exclusión de una persona de los rendimientos de un sistema, se producen consecuencias en cadena: "las familias que viven en la calle y no tienen una dirección fija no pueden matricular a sus hijos en la escuela. O quien no tiene documentación personal queda excluido de las prestaciones sociales, no puede ser elector, ni casarse legalmente" (Luhmann 1998:191).

El problema de la exclusión social parece cumplir con las dos condiciones descritas para especificar la función del sistema de cooperación: es suficientemente abstracto para que pueda afectar a todos y suficientemente específico como para tratarlo por mecanismos especializados. De cualquier modo, la evolución social ya había previsto este problema. A fines del siglo XIX la construcción del Estado social europeo apuntaba al tratamiento de los problemas de exclusión social en una sociedad que se diferenciaba crecientemente y que debía enfrentar los efectos de la industrialización. En línea con esta idea original, el siglo XX transformó el Estado en una estructura de bienestar responsable por la integración general de la sociedad: "debe representar la cima jerárquica y centro de la sociedad que requiere de supervisión y control para contrarrestar la dinámica centrífuga de los diversos intereses y racionalidades parciales utilitariamente orientadas" (Willke 1996:22). Sin embargo, la creciente aceptación de la solución de problemas sociales condujo al Estado de bienestar a fines del siglo XX a múltiples crisis. En palabras de Luhmann: "Esto llevó a ampliar los límites financieros, a burocratización y juridificación y a una creciente dependencia de la vida diaria de decisiones estatalmente controladas" (Luhmann 1990b:170). Paralelamente, dada la creciente autonomía ganada por otras esferas sistémicas, los esfuerzos de planificación del Estado de bienestar se hacen cada vez menos efectivos y la paradoja de la relación entre política y otros sistemas sociales aumenta: si el Estado de bienestar se muestra dispuesto a mayor participación en los problemas sociales, los otros sistemas lo sobrecargan con exigencias que se derivan de problemas generados por políticas estatales ineficientes. Las soluciones propuestas por el Estado crean problemas porque problemas anteriores exigieron soluciones estatales; con esa dinámica, el Estado de bienestar logra sostenerse a sí mismo durante un siglo hasta la inmanejabilidad de crisis financieras, políticas o problemas de juridificación de esferas sociales —o, puesto en términos habermasianos, hasta una colonización insoportable del mundo de la vida (Habermas 1988). 
Con sistemas crecientemente diferenciados, la crisis del Estado de bienestar o del Estado desarrollista latinoamericano era previsible: la función de control y responsabilidad por los problemas sociales de cada esfera pasa a ser reemplazada por una función de coordinación de las distintas lógicas diferenciadas: "el estado opera como instancia de coordinación entre los diversos sistemas funcionales. Vale decir, ha de desarrollar la interdependencia existente entre el sistema económico, jurídico, educativo, etcétera. Esta 'coordinación sistémica' la lleva a cabo el estado a través de múltiples formas de regulación y supervisión” (Lechner 1999:51).

Siendo así, el problema de la exclusión social deja de ser responsabilidad directa del Estado y se transfiere a cada sistema funcional. La política puede generar incentivos a la inclusión, pero no logra incluir directamente; cada esfera tiene que preocuparse de ello. Pero sólo la política se autodescribe desde la perspectiva del bonum commune y sólo ella puede tomar decisiones colectivas vinculantes vía derecho. Por ello, la exclusión como problema no queda entregada a una instancia que centralice las demandas o que traduzca las pretensiones de inclusión en rendimientos específicos. La política desarrollista latinoamericana podía incluir económicamente por razones de la 'inmoralidad de la pobreza', o incluir educativamente por razones de 'justicia social' a través de programas específicos para cada caso: políticas de pleno empleo, de unificación de la educación escolar. Hoy puede intentar coordinar autonomías para que ello se produzca, pero carece de los medios de control para inducir imposiciones. La economía, por su parte, incluye a quien dispone de dinero y excluye a quien no lo posee; la educación incluye a quien tiene las condiciones para cumplir con los requisitos de la selectividad pedagógica y excluye a quien no los logra constatar. Es decir, la exclusión se multiplica, tanto porque todo sistema excluye como también porque lo hace según su propio criterio, y el Estado, que había sido la instancia que absorbía esa complejidad, hoy ya sólo puede coordinarla.

Vistas las cosas en esta perspectiva evolutiva, no es casualidad que en la segunda mitad del siglo XX organizaciones orientadas a tratar con múltiples problemas de exclusión hayan tenido un mayor auge que en épocas anteriores. Paulatinamente, ellas comenzaron a ocupar el espacio que los intentos crecientemente estériles de intervención estatal dejaban sin ocupar. El propio Estado desarrolló el principio de subsidiariedad para ajustarse a esta nueva situación en la que la responsabilidad operativa por la exclusión pasa crecientemente a manos de organizaciones especializadas en tal tarea, en el marco de un sistema cuya función comienza a quedar definida así por la transformación de la exclusión en inclusión. 


\section{Semántica y estructura}

La diferenciación de un sistema de la cooperación parece apuntar entonces al tratamiento de la exclusión. Tanto en una dimensión semántica como en una estructural, determinados desarrollos independientes se acoplan a esta función, la impulsan y contribuyen a su especificación: una semántica definida por la evolución de una moral de tipo universalista representada en la semántica contemporánea de los derechos humanos (a), y otra estructural, derivada desde los propios requisitos sistémicos por asegurar la inclusión social en sus rendimientos diferenciados (b).

(a) El Estado liberal de la modernidad temprana proclamó los derechos civiles bajo la forma de la individualidad para asegurar al hombre la autonomía de acción y voluntad que prometía la disolución del orden antiguo estratificado; el Estado social de la modernidad clásica pretendió mediante derechos sociales crear las condiciones para la integración de los individuos en las instituciones que había desarrollado. La semántica actual de los derechos humanos, en un contexto estatal de crisis de las fórmulas del bienestar y de su transformación en un Estado de supervisión con preocupaciones de coordinación social, busca reintroducir una mirada universal en un contexto individualizado, es decir, no se trata únicamente de que el individuo ordene su conducta en conformidad a principios valóricos, sino que además se debe esperar que otros también hagan lo mismo en torno a los mismos valores. De los derechos humanos, esta tercera generación de derechos resulta como exigencia de que "uno no sólo debe extender los valores propios a los valores de los otros - a favor de los intereses de los pobres, de los desposeídos, de los hambrientos, del 'Tercer Mundo'- sino que se debe exigir también que los otros se solidaricen con este programa axiológico" (Luhmann 2002:632). De este modo, los derechos humanos son básicamente una normativización de las expectativas normativas, es decir, en términos de expectativas se cierra éticamente el círculo de las preferencias morales y se las entiende por ello universalizadas.

Más allá de la discusión específica por el cumplimiento y posibilidad de seguir jurídicamente estos derechos, ellos entregan un panorama de lo que puede ser calificado como exclusión en el funcionamiento sistémico moderno. Se habla de derechos sociales como nivel de vida suficiente, protección de salud, seguridad social, propiedad, trabajo, medio ambiente equilibrado; de derechos culturales como respeto de identidad, a la información, a la educación, a participar de vida cultural; o de derechos de personas en situación vulnerable, como derechos del niño, de la tercera edad, de la mujer a la igualdad, de los extranjeros, de las minorías, de los pueblos autóctonos (Meyer-Bisch 2000). Se trata en este caso de derechos de los individuos como tales, es decir, de derechos que se sitúan más 
allá de la pertenencia política del individuo a un Estado; en otras palabras, de derechos cosmopolitas:

\begin{abstract}
El núcleo innovador de esta idea reside en la consecuencia de la transformación del derecho internacional, en tanto que derecho de los Estados, en un derecho cosmopolita en tanto que derecho de los individuos: ahora éstos ya no son sujetos de derecho sólo en tanto que ciudadanos de sus respectivos Estados, sino también como miembros de una comunidad cosmopolita sometida a una autoridad superior. (Habermas 2006:122)
\end{abstract}

Este decantamiento moral de derechos cosmopolitas opera frente a la exclusión local en un doble sentido: indica semánticamente en cada espacio territorial cuándo hay transgresión o no cumplimiento de derechos; pero, por otro lado, dado el escaso desarrollo evolutivo de los mecanismos jurídicos de un derecho mundial, genera decepción de expectativas ante el incumplimiento de esos derechos. Las organizaciones cuyo problema central es la exclusión social tratan in situ lo que globalmente desde una perspectiva moral cosmopolita aparece como exclusión. Si esto hace superflua la diferenciación de una instancia central a nivel mundial que centralice estas expectativas, es algo que sólo la evolución puede indicar. Por ahora pareciera haber al menos una línea de conexión que aún no se traza directamente entre los organismos mundiales de protección de derechos humanos y la organización jurídica nacional encargada de tratar problemas de exclusión. Esta distancia para el aseguramiento jurídico de las expectativas normativas ancladas en los derechos humanos, puede ser un elemento estructural altamente relevante para la consolidación de la dimensión autoorganizativa y autorregulativa de un sistema mundial de la cooperación, cuya función es la transformación de la exclusión en inclusión o para su acceso a un nuevo momento del desarrollo de su autorreferencia, sea a la autoproducción sistémica o a su autopoiesis.

(b) Desde un punto de vista estructural, la exclusión también se vuelve problemática para los sistemas sociales cuando ella es demasiado alta. Las crisis financieras pueden entenderse como la renuncia a la inclusión económica en un determinado espacio; también la falta de puestos de trabajo puede conducir a crisis económicas estructurales que a su vez se expresan en inestabilidad política. A su vez, las crisis políticas de Estados nacionales pueden observarse como la exclusión de las condiciones de operación jurídica de un Estado de derecho y conducir a inestabilidad económica; las crisis educativas, en tanto, pueden medirse en las tasas de analfabetismo o deserción escolar, o en los índices de repitencia de los que no cumplen con las condiciones de selectividad pedagógica; las crisis de salud, por su parte, 
pueden también observarse en las tasas de morbilidad de una población específica o en el acceso a condiciones sanitarias adecuadas en una región determinada. Es decir, la exclusión de los rendimientos sistémicos genera problemas que el propio sistema puede intentar compensar con operaciones propias o en acoplamiento con instancias externas.

Desde el punto de vista de los sistemas funcionales también existen, por tanto, incentivos a la inclusión. Los sistemas diferenciados apuntan constantemente a la inclusión de personas en sus modos particulares de funcionamiento. La secuencia se podría formular del siguiente modo: mientras más inclusión generen, los sistemas funcionales tienen mayores probabilidades de reproducir sus propios elementos y, al hacerlo así, refuerzan las condiciones que aseguran su existencia. Es decir, por ejemplo, mientras más larga sea la jornada escolar, mientras más formación continua se requiera, mientras más calificación laboral vía certificación se exija, más legitimidad e institucionalización gana el sistema educativo. Una persistencia de la exclusión de los rendimientos sistémicos puede hipotéticamente conducir a un colapso, el que en términos reales es de cualquier modo improbable dada la densidad autopoiética de los sistemas hasta hoy diferenciados y de las sinergias existentes entre sistemas por efecto de los acoplamientos estructurales. Sin embargo, como indica Luhmann: "si se presta atención a los desarrollos estructurales dentro de estos sistemas, no podrán ignorarse por más tiempo los efectos de una creciente solidez y prevalencia de la diferencia entre inclusión y exclusión" (1998a:192).

Bajo estas condiciones, las organizaciones orientadas al tratamiento de problemas de exclusión pueden entenderse como un espacio en diferenciación que la evolución social comienza a distinguir cuando los niveles de exclusión alcanzan un nivel tal que ponen en riesgo la autopoiesis del propio sistema que provoca la exclusión. La consolidación de un sistema de la cooperación puede encontrar en ello un campo abierto para operaciones especializadas en la función descrita.

\section{Medios de comunicación simbólicamente generalizados: excurso teórico}

Para consolidarse como tal, la función sistémica debe resolver uno de los problemas centrales que la diferenciación funcional pone en movimiento en el contexto de las sociedades modernas: la vinculación de la operación clausurada de los sistemas con la motivación individual a desarrollar comunicación y acción en el sentido de la función. Si la teoría de sistemas entiende la sociedad como un orden emergente de comunicación respecto del cual el individuo se posiciona en su entorno, es necesario constatar el modo en que el acoplamiento entre conciencia y comunicación 
tiene lugar. Para ello, deben existir mecanismos que logren regular la orientación de las comunicaciones al interior del sistema y a la vez sean lo suficientemente abstractos como para motivar a nivel de la conciencia individual comunicaciones y acciones que se acoplen a la función sistémica. A estos mecanismos la teoría de sistemas los ha denominado medios de comunicación simbólicamente generalizados, esto es, constelaciones significativas de selectividad coordinada que posibilitan entendimientos comunes, expectativas complementarias y temas determinables, a saber: la verdad, el amor, la propiedad, el dinero, el arte, el poder, la validez legal (Luhmann 1997a:316 y ss.).

Si la teoría de los medios permite integrar en un campo problemático motivación de la conciencia y comunicación para dar cuenta, por un lado, de la constitución de la sociedad y para indicar a la vez cómo la conciencia se motiva por el acoplamiento con selectividades sociales específicas, es necesario entonces comenzar el análisis con la representación de dos conciencias, el mínimo necesario para la comunicación. Las figuras de alter y ego han servido a este propósito. Puesto esquemáticamente, los medios permiten desarrollar los rendimientos siguientes:

- Combinan selección y motivación de alter y ego, y las transforman en un resultado que es superior y exterior a ambos: la sociedad, la cual en todo caso sucumbiría sin este acoplamiento, sin esta separación permanentemente integrada de conciencia y comunicación.

- Ganan terreno para la sociedad al inducir la aceptación del medio para tratar nuevos temas o temas antiguos de manera distinta, por ejemplo, promoviendo la regulación legal del uso de nuevas tecnologías o al acoplar las relaciones económicas a semánticas éticas por medio de fórmulas como la responsabilidad social.

- Transforman probabilidades de negación en probabilidades de aceptación mediante una técnica de codificación binaria que recogen del lenguaje (aceptación/rechazo, sí/no) y que separa el medio en un valor positivo y un valor negativo. El valor positivo indica la motivación a usar el medio, por ejemplo: pagar con dinero si se quiere utilizar un bien que no se dispone, o confiar en el conocimiento verdadero de otro si el otro cumple con las exigencias del sistema científico. El valor negativo indica la motivación al rechazo de otras alternativas para las mismas constelaciones, por ejemplo: el robar para obtener un bien o la introspección para acceder al conocimiento.

En el transcurso de la evolución social, en especial en los últimos tres siglos, la diferenciación de los medios simbólicos ha contribuido a una diferenciación 
de sistemas de modo tal que cada sistema se ha especializado, por medio de su estructura social (procedimientos) y su semántica (legitimaciones), en la motivación a la selección de un medio específico para la constelación significativa de que se trate: uso del dinero en economía, del poder en la política, de la validez legal en el derecho, de la verdad en la ciencia, del amor en la esfera de las relaciones íntimas (Luhmann 1997a). Mediante estas constelaciones estructuradas en la forma de sistemas sociales se hace efectiva para los individuos la aceptación y expansión de sus propias selecciones sin la necesidad de entregar mayores justificaciones del porqué de ellas: se puede aceptar un conocimiento como científico porque ha sido generado por procedimientos científicamente establecidos, se puede vender una propiedad a desconocidos siempre que paguen lo que se cobra, se puede aceptar la culpabilidad jurídica de alguien aun cuando aquel haya sido un 'buen hombre' si la decisión del tribunal ha sido procedimentalmente tomada. En cada caso, no se precisan razones adicionales para aceptar o expandir la selección, aunque ellas siempre puedan darse para tranquilidad de los individuos. El logro evolutivo de la diferenciación y construcción de sistemas sociales en torno a los medios de comunicación simbólicamente generalizados reside en que la fuerte motivación que ejercen a nivel de la conciencia individual a la aceptación de la selección social en cada campo diferenciado, libera al individuo de tener que argumentar cada selección o de tener que evaluar (moralmente, políticamente, estratificatoriamente) a cada otro individuo al cual la selección va dirigida. Ello a la vez institucionaliza el funcionamiento sistémico y otorga tiempo al individuo para desarrollar su propia individualidad, para volverse más individuo.

Para precisar el modo concreto a través del cual las selecciones individuales se acoplan al funcionamiento sistémico, es preciso interrogarse por el modo en que a nivel del individuo opera el proceso de selección. Dos condiciones se requieren para esto: el procesamiento personal de la información como vivencia o como acción y la presencia al menos de dos unidades que puedan procesar la información como vivencia o como acción. En relación a lo primero, vivencia y acción son los dos modos que el individuo tiene para expresar su individualidad (Luhmann 1991). Por medio de la vivencia el individuo reconoce el mundo como significativo para él y puede encontrar en sí mismo justificaciones a los estados externos percibidos; por medio de la acción el individuo atribuye a una unidad discreta (un sistema, propio o ajeno) lo que observa en el mundo. En relación a lo segundo, el procesamiento de la información se transforma en comunicación social sólo cuando un individuo y otro individuo operan coordinadamente, es decir, cuando ego y alter pueden atribuirse vivencias y acciones en forma paralela. De ello emerge la doble contingencia de la comunicación, pues lo que ninguno de los dos puede hacer es actuar con las acciones del otro ni vivenciar con las vivencias del otro, 
por tanto, frente a un evento en el mundo, alter y ego pueden vivenciar y actuar coordinadamente.

Bajo estas condiciones, según se trate de una vivencia o de una acción de alter o de ego, las motivaciones al uso de los medios simbólicos se construyen de manera diferenciada. El esquema siguiente refleja las posibilidades combinatorias (con variaciones Luhmann 1971, 1997a, 1998b, 1998c, Luhmann y Di Giorgi 1998). Su forma de lectura siempre va de alter a ego:

\begin{tabular}{|c|c|c|c|}
\hline & & \multicolumn{2}{|c|}{ EGO } \\
\hline & & Vivencia & Acción \\
\hline \multirow{2}{*}{ ALTER } & Vivencia & $\begin{array}{c}\text { Alter desencadena una } \\
\text { vivencia en ego a través de la } \\
\text { comunicación de su vivencia } \\
\text { |VERDAD| |VALORES| }\end{array}$ & $\begin{array}{c}\text { La vivencia de alter lleva a } \\
\text { una correspondiente } \\
\text { conducta de ego } \\
\mid \text { AMOR } \mid\end{array}$ \\
\hline & Acción & $\begin{array}{c}\text { La acción de alter selecciona } \\
\text { una vivencia en ego } \\
\text { y es aceptada como tal } \\
\text { |PROPIEDAD-DINERO| |ARTE| }\end{array}$ & $\begin{array}{c}\text { La acción de alter da lugar a } \\
\text { una correspondiente } \\
\text { acción en ego } \\
\text { |PODER| } \\
\text { |VALIDEZ JURÍDICA| }\end{array}$ \\
\hline
\end{tabular}

Los cuatro espacios interiores constituyen la sociedad con sus medios simbólicos y sistemas diferenciados, es decir, el orden emergente de la comunicación. En tanto, los espacios exteriores, esto es, las posibilidades de vivencia y acción de alter y ego, se reservan para los individuos con su potencial de selección en el entorno de la sociedad. El acoplamiento tiene lugar entonces por la motivación al uso del medio que la construcción de sistemas promueve ante la conciencia individual (comunicación $\rightarrow$ conciencia) y la selección de temas en la sociedad que alter y ego realizan a través de sus vivencias o acciones además de la atribución de vivencias y acciones a otros (conciencia $\rightarrow$ comunicación).

Los sistemas que evolutivamente se forman bajo la selección de estos medios son la ciencia en torno al medio verdad, la religión en función de cierto tipo de valores, la familia o el sistema de la intimidad en torno al amor, la economía en la constelación del dinero, el sistema del arte en relación a lo que es calificado de artístico, la política en el medio del poder y el derecho en el espacio de la validez legal. Se observa a primera vista la ausencia de algunos sistemas con pretensiones de diferenciación: la salud, el deporte, los medios de comunicación de masas. No parece haber un medio simbólico decantado para estos casos, aunque de todos modos codifican su función (informar/no-informar, entretener/no-entretener, por 
ejemplo en el caso de los medios de comunicación de masas). De ello debe concluirse que de ningún modo es posible dar por finalizado el catálogo de medios. La sociedad evoluciona. Ahora mismo nuevas constelaciones significativas están emergiendo, como aquella que en estas páginas nos interesa.

\section{Vl. Medio de comunicación simbólicamente generalizado colaboración}

La consolidación de la diferenciación de un sistema global de la cooperación dependerá en buena medida de que un medio de comunicación simbólicamente generalizado se especialice en la transformación de la exclusión en inclusión y controle con ello la función sistémica. Si un sistema de la cooperación social encuentra su espacio específico en el tratamiento de la exclusión en sociedades posbienestaristas, entonces aquel requerirá de una constelación simbólica lo suficientemente específica para asegurar que una acción de cooperación sea vivenciada como posibilidad de inclusión social, y lo suficientemente abstracta para que abarque desde acciones de cooperación generalizadas (con 'países en desarrollo') hasta individuales (con 'personas en situación de calle'). Esta posición parece estar siendo ocupada por la constelación simbólica de la colaboración.

Un medio de comunicación simbólicamente generalizado no es una palabra o un término; es una constelación significativa de selectividad coordinada que otorga entendimientos comunes, expectativas complementarias y temas determinables (Luhmann 1997a). Por constelación significativa se deben entender referencias de sentido múltiples que se entrecruzan y se sostienen mutuamente para perfilar un espacio comunicativo diferenciado en el cual se coordine la doble contingencia de la selección de alter y ego, y aparezca como selectividad social coordinada en el mundo. Si la colaboración ha comenzado a formar una constelación significativa de esta naturaleza, entonces la constatación de que ella tiene lugar es la puesta en movimiento de múltiples vectores de comunicación y acción, y múltiples horizontes simbólicos y semánticos que hacen de una acción indefinida, una acción colaborativa en el marco de relaciones sistémicas de cooperación. La prueba de que ello efectivamente resulta así es que a través de esos vectores simbólicos y semánticos de acción y comunicación, tanto alter como ego, desde sus posiciones particulares e irrepetibles, observen la selectividad social de un modo coordinado, es decir, que observen lo que un observador de segundo orden también observaría: un tipo de relación específica respecto de la cual todos podrían concordar en denominar colaborativa o en atribuirle significados cercanos también presentes en la constelación significativa del medio simbólico, como relación cooperativa, solidaria o incluso caritativa. 
La incorporación (Aufhebung habría que decir más correctamente) de estas múltiples significaciones en el medio simbólico es condición para que un medio opere como tal. Los medios simbolizan, no diabolizan, es decir, unen, no separan, aunque por cierto separan del exterior de la constelación respectiva. Las diferenciaciones semánticas que luego emergen son distinciones al interior de un sistema cuya unidad se define desde el medio simbólico. Por ello, el medio simbólico debe ser lo suficientemente abstracto para incorporar el contenido semántico y los distintos patrones conductuales acoplados a esas distinciones internas y hacer que todas ellas se entiendan pertenecientes al sistema: desde las acciones misioneras hasta la cooperación internacional de la Organisation for Economic Cooperation and Development (OECD). Si el tipo de colaboración es sacrificial, altruista, recíproca o pragmática (Arnold y Thumala 2006) es una distinción secundaria para la formación del sistema, es una re-entry en su interior (Spencer-Brown 1979), tanto como para el medio simbólico poder, la democracia, el autoritarismo, el totalitarismo son distinciones internas de la política, o como para el medio dinero, el efectivo, las tarjetas de crédito, los cheques, bonos o pagos a futuro lo son en la economía. Si el medio simbólico contribuye a la formación de sistema y logra abstracción en ese proceso, la colaboración debe soportar distintos modos de colaborar; y si en ese mismo proceso logra especificidad, alter, ego y el observador de segundo orden deben entender que los distintos modos de colaborar se orientan sistemáticamente a la activación de la función: la transformación de la exclusión en inclusión.

En referencia al cuadro en la sección $\mathrm{V}$, la colaboración como condensación de la selectividad social específica que apunta a la transformación de la exclusión en inclusión en los términos descritos en las secciones II, III y IV, se ubica en la constelación acción de alter/vivencia de ego, la misma constelación del dinero y el arte. En el campo significativo del medio de comunicación simbólicamente generalizado colaboración, alter desarrolla una acción que es vivenciada por ego como libertad de inclusión en algún espacio social específico. Por medio de la acción de alter, ego es liberado del obstáculo que impedía una inclusión concreta y que motiva la conducta colaborativa de alter.

Puesto que se ubican en la misma constelación de relación alter-ego, una comparación de la colaboración (probablemente el menos diferenciado de los medios simbólicos) con el dinero (probablemente el más diferenciado de ellos), puede ser heurísticamente ilustrativa. En términos de Luhmann, el dinero es "libertad transmisible de elección limitada de bienes. Se logra esta libertad a través de la abstracción de una posibilidad de cambio que, reducida a una limitación cuantitativa, deja abierto cuándo, con quién, a través de qué objeto y bajo qué condiciones el poseedor del dinero llevará a cabo una transacción" (Luhmann 2000:62). Alter 
desarrolla una acción de pago y mediante ella abre en ego múltiples vivencias de ejecución de otros pagos; cuando esas vivencias se transforman en acción de pago hay sistema económico y cuando ello se reproduce en el tiempo hay autopoiesis de la economía.

El modelo de la colaboración es similar. Colaboración es libertad transmisible de elección limitada de posibilidades de inclusión. Cuando tiene lugar una acción colaborativa, cualquiera sea ella, alter elimina o debilita mediante su acción restricciones de exclusión que abren o probabilizan posibilidades en todo caso limitadas de inclusión para ego. Alter no resuelve los problemas generales de exclusión de ego, pero le otorga a ego mayor libertad de elección, incrementa la contingencia de las posibilidades de elección que desde ego se vivencian ahora como mayores a las que existían antes de la acción de alter.

Esto no significa reducir la colaboración a una unidad cuantitativa como el dinero. De entre los medios simbólicos sólo el dinero logra este nivel de especificidad y por eso adquiere la posibilidad de cuantificar cada relación, incluso las no económicas. Con ello diaboliza, separa lo que otros medios simbolizan: cuando cuantifica relaciones en el medio poder o validez jurídica hay corrupción; cuando cuantifica relaciones íntimas hay amor por interés, cuando cuantifica relaciones artísticas hay monetarización del arte. La colaboración no tiene posibilidad de cuantificación; se puede colaborar más o menos, pero no 1 ó 100. Probablemente por ello no pueda especificar más la libertad que transmite en el sentido de hacerla pronto circulable como nueva acción de colaboración, es decir, que ego pase a ser un alter que colabora. Cuando la libertad que la colaboración transmite se vivencia, ello no supone siempre una exigencia más o menos clara de volver a ponerla en juego por medio de otra acción que reproduzca el sistema.

En esto último radica la razón principal por la que el sistema de la cooperación no haya alcanzado hasta hoy una operación autopoiética y se encuentre en un momento de autoorganización y autorregulación, con algunos episodios de autoproducción, como lo observáramos más arriba a base del esquema de temporalización de la autorreferencia de Teubner. Las presiones para volver a introducir la libertad ganada bajo la forma de una acción de colaboración no están por ahora de modo pleno incorporadas en términos motivacionales. La codificación de derechos de inclusión de tipo cosmopolita que hace visible la exclusión tanto a nivel mundial como en cada espacio local, es un avance en esta dirección. Un sentido de unidad de orden moral no anclado en pertenencias políticas, nacionales o étnicas, sino en la pertenencia de cada individuo al mundo puede ejercer una mayor motivación para la acción colaborativa. Por otro lado, las propias exigencias de funcionamiento sistémico tienden a orientar la motivación hacia la inclusión cuando ese funcionamiento se ve amenazado por niveles altos de exclusión. 
Pero para ambos casos hay limitaciones. La consideración de ciudadanos del mundo exige un alto nivel de abstracción para el cual la reflexión filosófica está bien preparada, pero no la acción cotidiana, más concreta e históricamente situada (Rorty 1996). Por otra parte, una ciudadanía mundial supone haber transformado el mundo en comunidad (Gemeinschaft), lo que requiere haber solucionado primero el problema de la doble contingencia de la comunicación en una sociedad (Gesellschaft) de sistemas funcionales diferenciados que se resisten a la unidad moral de la razón práctica. Esto puede llegar a suceder en términos evolutivos, pero todo puede suceder en términos evolutivos. Como sería posible también que, dada la diferenciación funcional de sistemas como modo dominante de organización de las sociedades modernas, la idea de ciudadanía mundial se acople semánticamente a un sistema de la cooperación crecientemente diferenciado como regla de codificación de las condiciones de exclusión.

La motivación a la colaboración derivada de un funcionamiento sistémico con altas cuotas de exclusión ciertamente existe y ha contribuido a la formación del sistema pero, por otro lado, los sistemas toleran niveles de exclusión mayores de los que los afectados son capaces de soportar. Ningún desempleado queda satisfecho al comprender su situación como parte de la tasa de desempleo normal de una economía capitalista. Pero esto presiona débilmente a los sistemas; ellos sólo fomentan la inclusión cuando sus procesos autorreferenciales se ven afectados: inclusión de trabajadores migrantes en la economía nacional después de situaciones bélicas, inscripción electoral en la política ante el envejecimiento del padrón, trabajo pastoral en la religión cuando disminuyen los fieles, fomento a la investigación cuando la producción científica escasea. Por estas razones, ego por lo general carece de una motivación fuerte para transferir libertad de inclusión una vez que la ha ganado. Las dificultades para la autopoiesis de la colaboración radican en estas razones que permiten a ego diferir de modo impreciso la transferencia de la libertad ganada. En la economía esto no se puede hacer; incluso cuando ego quiere diferir el uso del dinero, lo ahorra, con lo que entrega toda su libertad de uso a otros (generalmente a la banca privada), a no ser que ahorre bajo el colchón. La colaboración, por el contrario, permite a ego mantener la libertad de inclusión que recibe de alter y prolongarla en el tiempo: para la educación de los hijos, para la vejez de los padres, para inclusiones de grupos internos cuando ego es un país que recibe cooperación internacional. $\mathrm{O}$ incluso permite no usarla, dado que la motivación a hacerlo que entrega la selectividad social no es fuertemente vinculante.

Por todo esto, condición de la consolidación autopoiética del sistema de cooperación es que el medio se emplee con celeridad, que quien recibe una libertad de inclusión la transmita a otros mediante acciones similares, no necesariamente a los mismos desde los cuales fluye la acción que promueve la inclusión, sino a otros 
indeterminados que también se vivencian en situación de exclusión. Por ello, el medio de comunicación simbólicamente generalizado de la colaboración no exige reciprocidad a la manera clásica del don de Mauss. La colaboración en sociedades complejas modernas en la forma de un sistema de cooperación no sólo puede establecerse como colaboración recíproca, sino también con otros cercanos o con otros indeterminados y abstractos. Lo central para la formación del sistema es que, mediante la acción, alter ponga a disposición de ego libertad de inclusión, que ego lo vivencie de ese modo y que esto se haga continuamente.

\section{V11. Fórmula de contingencia solidaridad}

Cuando un sistema ha logrado un determinado nivel de diferenciación, al menos de autoorganización y autorregulación, desarrolla formulaciones semánticas que permiten a organizaciones y a actores acoplados al sistema autodescripciones unitarias que reflexivizan las operaciones del sistema desde lo que Habermas llama perspectiva interna. Esto es lo que la teoría de sistemas denomina fórmula de contingencia. Las fórmulas de contingencia son indicaciones que, por un lado, "no deben perder relación con las consumaciones de sentido de la vida diara" (Luhmann y Schorr 1993:74) y, por otro, designan un "ofrecimiento con el que el sistema se identifica como idea, como principio, como valor" (Luhmann 2002:280). Ejemplos de fórmulas de contingencia son: la escasez en el sistema económico, la legitimidad para el sistema político, la justicia para el sistema jurídico (Luhmann 1997a), la idea de un dios único en el sistema religioso, la formación o la capacidad de aprendizaje en el sistema educativo (Luhmann 2002). Su desarrollo emerge evolutivamente en estricta relación con la especificación de la función y sus rendimientos son los siguientes:

- Permiten una referencia de sentido más o menos unívoca entre sistema y entorno; tanto el sistema se reconoce y describe por medio de la fórmula, como también el entorno puede observar que lo que se hace en el sistema es lo que la fórmula indica. La fórmula motiva coordinación de expectativas entre sistema y entorno. Quien quiera formación o incrementar su capacidad de aprender sabe que no debe acudir a la política.

- Posibilitan una autoidentificación de las organizaciones y actores acoplados al sistema con las comunicaciones dominantes al interior del sistema. Tanto alter como ego entienden que mediante sus vivencias y acciones ponen en movimiento lo que la fórmula describe. El comprador sabe que por medio de la compra está supliendo una escasez propia. 
- Contribuyen por medio de una descripción semántica a la operación del medio simbólico del sistema respectivo y, con ello, a la reproducción de su función. Para obtener justicia el derecho debe asegurar expectativas normativas mediante decisiones jurídicamente válidas.

- Permiten al sistema unificar bajo una indicación semántica las múltiples diferenciaciones internas, las múltiples re-entry que la operación sistémica genera. En la religión, cada distinción debe trazar la genealogía de su origen divino.

En este sentido, la fórmula de contingencia no es operativa, es semántica que se aplica con fines operativos: para coordinar sistema y entorno, para dar unidad a sus actores, para apoyar la función y para sintetizar las diferencias al interior del sistema. Son fórmulas de contingencia porque reducen la indeterminabilidad del mundo y la hacen semánticamente determinable, incluso para aquellos en el entorno del sistema. Por todo esto, la fórmula de contingencia no debe confundirse con el medio simbólico (cfr. Hagen 2000, Zulueta 2003). Por ser semántica, la fórmula es histórica; condensa significados temporalmente situados que nominalizan la variabilidad de la constelación significativa del medio simbólico evolutivamente diferenciado. El medio simbólico pone en operación todo el entramado sistémico; la fórmula de contingencia lo refleja y lo devuelve sobre sí mismo por medio de una designación uniforme asequible para observadores diversos.

En el caso del sistema de la cooperación, la solidaridad opera como fórmula de contingencia. Se habla de la solidaridad desde el interior y el exterior; se la emplea como objetivo, como principio y como valor (cfr. Dockendorff 1995). Con ella se designa un esquema de búsqueda de acciones que propenden a la colaboración de alter hacia ego para la transformación de la exclusión en inclusión. Cada expectativa estructurada de esta forma mueve a su búsqueda en el sistema de la cooperación, con lo que este probabiliza crecientemente su recursividad. Cada vez menos la política está en condiciones de dar esa respuesta debido a su pérdida de capacidad de control de otros sistemas; tampoco la familia alcanza para las múltiples exclusiones dada su especialización en la individualidad por la vía del medio amor (Luhmann 1985). La religión, en tanto — sistema con el que la cooperación puede encontrar aún una alta integración - orienta los problemas de exclusión hacia un campo semántico y operativo distinto al de la colaboración, y el derecho sólo puede observar la exclusión si ella ha sido traducida en codificación jurídica. Es decir, para la solidaridad hay que acudir a aquellas organizaciones que nombramos más arriba: organizaciones de voluntariado; de cooperación internacional; de ayuda al desarrollo; de caridad, de ayuda en salud, educación, vivienda; de lucha contra la discriminación en distintos espacios; de superación de la pobreza, o 
autoconstituirse para la solidaridad en organizaciones de autoayuda. En cada caso, la respuesta a la pregunta por la designación de lo que en ellas se hace podrá ser, con mayor o menor intensidad, solidaridad: solidaridad con regiones del mundo (con África, América Latina, Asia, Europa oriental), solidaridad con grupos (los necesitados, los pobres, las minorías, los oprimidos, los discriminados, los hijos de Dios, los hambrientos, los homeless), solidaridad con individuos (amigos, familia, con un alter-ego). Todos sabrán — gracias a la fórmula — que en esas organizaciones se trabaja por la solidaridad. Y los que no lo son tendrán claro, gracias también a la fórmula, que para ser solidarios hay que colaborar, transmitiendo mediante la acción libertad de elección limitada de posibilidades de inclusión.

Como término la solidaridad no es algo nuevo. Ya en el derecho romano la figura de la obligatio in solidum indicaba la responsabilidad solidaria (densa, sólida) de terceros frente a una deuda contraída (Herweg 2005). Con algo más de distancia, la idea aristotélica de teleia philia (lat. amicitia) y homonoia (lat. concordia) para referir aquello que mantiene unido al Estado y que semeja la forma de la amistad, de una amistad cívica, se orientan en una dirección similar (Kahane 1999). Asimismo, las formulaciones bíblico-cristianas de la fraternitas y la caritas expresan la idea universalista de la unidad en Cristo que obliga frente a otro (Brunkhorst 2002). Condensaciones de estas expresiones originales son recogidas por la fórmula de la solidaridad en la semántica política y religiosa de los siglos XVIII, XIX y XX, primero en la Revolución Francesa bajo la forma de igualdad y fraternidad, aunque más técnicamente en la idea rousseauneana de contrato social, como solidaridad del demos, una solidaridad que se oponía a la solidaridad cristiana universalista de la unidad de los hijos de Dios, en tanto esta — según Rousseau — alejaba el corazón de los hombres del Estado (Rousseau 1992). La sociedad civil de Hegel, por su parte, encontraba en las corporaciones ese equivalente funcional del cuidado entre próximos al interior de la familia (Nederman 1987), una figura que Durkheim (1985) reiteraría con posterioridad en la idea de asociaciones profesionales como unidades de integración en el marco de la solidaridad orgánica de la división social del trabajo.

En el campo de la doctrina social católica del siglo XIX es donde la semántica de la solidaridad se diferencia en una solidaridad cristiana y una solidaridad secularizada asociada a la construcción del Estado social. En su concepción más teológica, la solidaridad cristiana de la segunda mitad del siglo XIX entiende a Dios como libre creador de todos los hombres, como "primera razón de la humana solidaridad, a saber, que la libre creación hace de la humanidad entera una familia, y de Dios creador el Padre de la gran familia humana" (Félix 1880:310). Esta solidaridad fraternal 'de todos los seres colocados en los diversos grados de la jerarquía social', debe ser distinguida de la solidaridad del reparto predicada por el 
socialismo: “ $¡ O$ Oh! no, mil veces no; la solidaridad de que os hablo en este momento nada tiene en común con esta ley de reparto, o más bien, con esta ley de pillaje o de 'brigandaje' universal" (Félix 1880:319). La solidaridad fraternal es un lazo de unión a la 'humanidad universal' que obliga a "la responsabilidad en el mal y la comunión en el bien, entre todos los miembros del cuerpo de Jesucristo" (Félix 1880:339); esto mueve a curar un mal contagioso que, por la unidad en Cristo, no puede alcanzar a uno sin que sufran todos los restantes: "Aquí está la parte radiosa de nuestra solidaridad cristiana. ¡La comunión! [... ¿ ¿Qué hay más vasto y más universal que la comunión de los santos? ¿Quién se halla excluido, en la humanidad, de esta divina comunión de las almas humanas? Nadie. Si todos no forman aún parte de ella, todos están llamados a entrar en ella" (Félix 1880:345, 347).

La secularización de esta idea de solidaridad y comunidad universal tiene también fuerte presencia en las últimas décadas del siglo XIX y sirve como base, mediante la idea de cuestión social, para la formación del Estado social en medidas clásicas como el día de descanso semanal (Lord's day), el tiempo máximo de trabajo, la fijación de un salario mínimo, así como el aseguramiento de los trabajadores contra los riesgos de trabajo y vida. Medidas de este tipo surgen principalmente en países no católicos (Inglaterra, Alemania). En los predominantemente católicos (España, Francia, Bélgica), los sistemas de seguridad son más tardíos, pues en ellos la "caridad privada y las instituciones voluntarias son correspondientemente más activas y generosas" (Jannet 1892:145). En especial en Francia las asociaciones entre patrones y trabajadores (comités de patronage) sirven como antecedente de "provechosas instituciones de cooperación y ayuda mutua" (Jannet 1892:151), como las sociedades de beneficencia o las asociaciones cooperativas voluntarias estamentales (gilds), "donde empleadores y trabajadores se encuentran en igual pie, y donde se establece una hermandad religiosa de relaciones fraternales basada en la comunidad de la fe" (Jannet 1892:154). Aunque también en el lado externo de la fe la semántica de la solidaridad gana terreno a nivel mundial, como en la idea política de solidaridad de la clase obrera (Kallscheuer 2001) o más prácticamente en las mutuales de socorro (Mena 2005).

Con estas especificaciones semánticas de la solidaridad en el siglo XIX, ella comienza a adquirir su carácter de fórmula de contingencia de acciones diversas que propenden a la colaboración de alter hacia ego para la transformación de la exclusión en inclusión. El siglo XX sólo logra ampliar el espectro de la fórmula a un alcance universal que comprende Gemeinschaft y Gesellschaft: "El principio de solidaridad exige que nadie, que no pueda ayudarse a sí mismo, sea dejado solo por la comunidad en una situación tal de necesidad extrema que no sea capaz de llevar adelante una vida en dignidad (definición mínima). Además, la sociedad debe también, de manera adecuada, habilitar a los débiles para participar de los bienes 
culturales (formación) y de los éxitos económicos de una sociedad (definición óptima)" (Roos 2004:8). De este modo, la fórmula de contingencia solidaridad incluye cada vez más contingencia en su espectro semántico; se amplía tanto para condensar diversas conductas que por ello comienzan a quedar incluidas bajo el medio de la colaboración, como para designar significados diversos que a pesar de su distancia pueden ser considerados solidarios precisamente porque responden al modo de operación del medio simbólico al que la fórmula de contingencia se refiere:

El concepto de solidaridad, que hace algunas décadas era atribuido al lenguaje político cotidiano más bien de la terminología de izquierda, es hoy una palabra clave, por una parte, de la política social y de la política exterior y, por otro, de la política de defensa y seguridad que se plantea por una apertura mundial, tolerancia, así como por una cooperación social que cruce las fronteras nacionales. (Münkner 2001:2-3)

La ampliación de la contingencia absorbida en la fórmula de contingencia alcanza campos variados: solidaridad entre generaciones, con los excluidos, con los discapacitados, con los extranjeros, con el tercer mundo, con el medio ambiente. En el campo económico se expresa en el desarrollo de cooperativas y de una economía solidaria a nivel de la comunidad (Razeto 1993), y en la idea de comercio justo a nivel de la sociedad global (Münkner 2001). La concentración de estas perspectivas en la fórmula de contingencia indica la formación de una política social de la sociedad mundial (Heidenreich 2005), que se apoya sobre criterios universales unificados bajo la forma de una solidaridad de ciudadanos del mundo codificada en los derechos humanos (Habermas 2006) y en la secularización de la doctrina social cristiana. La fórmula entonces reconoce los límites de inclusión de la intervención del Estado nacional y condensa la observación hacia constelaciones estructurales de alcance supranacional (organizaciones, acuerdos y políticas internacionales, actores globales) y hacia semánticas universalistas (derechos humanos, cosmopolitismo, ecumene) que contribuyen a la formación de estructuras para la transformación de la exclusión en inclusión en lo que hemos denominado sistema de cooperación en la sociedad mundial.

\section{V111. Acoplamientos estructurales}

La alta abstracción que gana la fórmula de contingencia solidaridad indica los espacios de acoplamiento estructural que el sistema de cooperación construye. Por acoplamiento estructural hay que entender una relación del sistema con su entorno que 
no implica un contacto directo con las operaciones internas del sistema, pero que posibilita una conexión por medio de irritaciones mutuas que en cada sistema son integradas e incorporadas como parte de la propia autopoiesis. Los acoplamientos estructurales son por tanto estructuras digitalizadas, contribuyen a cada sistema por separado y a la vez al cofuncionamiento de esos sistemas en las operaciones que el acoplamiento especifique. En palabras de Luhmann: "acoplamiento estructural indica la transformación de relaciones análogas (simultáneas, continuas) en digitales, que pueden ser tratadas según un esquema o bien esto/o aquello, o caracterizadas por una intensificación de determinadas trayectorias de irritación recíproca acompañadas de una alta indiferencia frente al entorno en otras" (Luhmann 1997a:779).*

Casos de acoplamiento estructural entre sistemas diferenciados son los impuestos entre política y economía, la constitución entre política y derecho, la propiedad y el contrato entre derecho y economía, la organización universitaria entre ciencia y educación, la consejería de expertos entre ciencia y política o la certificación entre educación y economía (Luhmann 1997a:781ss). En todos estos casos, las estructuras de acoplamiento permiten poner a disposición la complejidad interna de un sistema para la operación de la complejidad de otro de una manera recíproca. Los acoplamientos son, por tanto, instancias duales, digitales de coordinación, que a la vez ganan su propia especificidad evolutivamente como organizaciones (universidades, centros de consultoría) o instituciones (contrato, constitución, certificaciones).

Puesto que no se trata de un sistema autopoiético, los acoplamientos estructurales del sistema de la cooperación no se decantan aún plenamente. Sin la adopción del punto de vista de la formación del sistema, los acoplamientos que la cooperación como sistema desarrolla pueden ser incluso categorizados como desdiferenciaciones de tipo ético en la autonomía operativa de sistemas diferenciados, como podría derivarse de la idea de responsabilidad social en la economía, la universalización de derechos humanos en la política mundial, la aplicabilidad social del conocimiento en la ciencia, la igualdad de oportunidades en la educación o la orientación hacia programas finalistas en el sistema jurídico (interés superior del niño, bienestar, equidad, integración, etc.). Es posible mirar todo ello — como por lo demás tradicionalmente se hace- bajo la perspectiva de una creciente institucionalización que el mundo de la vida ejerce sobre el sistema, como presiones de una razón práctica

* La traducción es imposible: "Auch hier besagt strukturelle Kopplung: Unformung analoger (gleichzeitiger, kontinuerlicher) Verhältnisse in digitale, die nach einem entweder/oder-Schema behandelt werden können, und ferner Intensivierung bestimmter Bahnen wechselseitiger Irritation bei hoher Indifferenz gegenüber der Umwelt im übrigen" (1997a:779). 
articulada comunicativamente por la legitimación de esferas de racionalidad con arreglo a fines que operan autorreguladamente (Habermas 1988).

Si como en este caso se atiende a la creciente diferenciación de un sistema de cooperación en la sociedad mundial, entonces cada una de esas formulaciones puede ser observada en tanto pistas a seguir para determinar el modo en que ese sistema forma acoplamientos estructurales con otros sistemas en el entorno. El reconocimiento de organizaciones e instituciones que cumplen funciones de acoplamiento en el sistema de la cooperación no es difícil, a pesar de no tratarse de un sistema autopoiético. Las organizaciones de ayuda al desarrollo y de voluntariado tanto a nivel nacional como internacional acoplan rendimientos colaborativos, políticos y económicos (a), la institución de la responsabilidad social acopla rendimientos colaborativos y económicos (b), como también la institucionalización de los derechos humanos acopla rendimientos colaborativos y jurídicos (c).

(a) El acoplamiento de colaboración, política y economía supone que las decisiones colectivas vinculantes que la política toma en el medio poder, definan programas políticos que motiven rendimientos económicos de transferencia de recursos orientados a transformar la exclusión en inclusión, es decir, a activar el medio de la colaboración. A nivel global, la Organisation for Economic Cooperation and Development (OECD), que agrupa a treinta países incorporados desde 1961 en adelante y que mantiene relaciones con setenta otros países, es un ejemplo organizacional supranacional de este acoplamiento. La propia OECD expresa su compromiso con el gobierno democrático y la economía de mercado a través del concepto de good governance en el plano del servicio público (democracia, derechos humanos, reducción de pobreza, protección ambiental) y la actividad corporativa (integridad de mercados, regulaciones corporativas, insolvencia, privatización) (OECD 2006a). Como organización de acoplamiento del sistema de la cooperación, su operación apunta a la asistencia al desarrollo, dividida en cooperación técnica, alimentación, situaciones de emergencia, condonaciones de deudas, costos administrativos y contribuciones a instituciones multilaterales. Los flujos monetarios crecientes con estos fines desde 1988 en adelante, se aprecian en la tabla siguiente:

Asistencia oficial al desarrollo de la OECD 1988-2005

Millones de dólares americanos

\begin{tabular}{|l|c|c|c|c|c|c|c|c|}
\hline $\begin{array}{c}1988-1989 \\
\text { Promedio }\end{array}$ & $\begin{array}{c}1993-1994 \\
\text { Promedio }\end{array}$ & 2000 & 2001 & 2002 & 2003 & 2004 & 2005 \\
\hline 46.339 & 57.484 & 53.749 & 52.435 & 58.292 & 69.085 & 79.512 & 106.477 \\
\hline
\end{tabular}

Fuente: OECD (2006b) 
Vista desde su dimensión política, tanto la OECD como otras organizaciones internacionales de este tipo: World Bank, United Nations Development Program, Internacional Monetary Fund, Internacional Development Association, African Development Fund, incorporan en su funcionamiento intereses nacionales, por ejemplo: aseguramiento del entorno político de inversiones en el extranjero para inversionistas nacionales, limitaciones al desarrollo de regímenes incompatibles con la democracia, regulación de las migraciones a los países miembros. Para el sistema económico este tipo de organizaciones fomenta la inversión extranjera de los países miembros, abre o expande mercados para bienes y servicios producidos en sus fronteras, y constituye para su propio mercado nacional fuentes de empleo significativas.

Que tanto el sistema político democrático mundial como una economía organizada monetariamente reproduzca su autopoiesis con ello, no impide que la complejidad de esos sistemas se ponga a disposición de la complejidad de la cooperación para poner en movimiento el medio simbólico de la colaboración y la función sistémica de transformación de la exclusión en inclusión. Si los flujos de dinero de la OECD o de cualquiera de las otras organizaciones supranacionales contribuyen a una transmisión de libertad de inclusión de alter hacia ego, es decir, si transforman exclusión en inclusión, entonces hay sistema de la cooperación. Que determinadas semánticas políticas puedan observar esto desde los intereses nacionales políticos o económicos particulares y atribuir un trasfondo estratégico a la cooperación, no obsta y, por el contrario, contribuye a que ella pueda ser también reconocida como solidaridad transnacional en la sociedad mundial (Simpson 2004) en un sistema que diferencia crecientemente su propia estructura y semántica.

(b) Esta misma cooperación internacional desarrolla estructuras e institucionaliza principios a nivel local que acoplan cooperación y economía. Conceptos como inversión en responsabilidad social, inversiones éticas o fondos éticos conectan el medio dinero y el medio crecientemente diferenciado de la colaboración a través de una inversión monetaria sujeta a criterios generalmente negativos que se apoyan en la protección de derechos cosmopolitas moralmente especificados. Se habla en estos casos del principio general de rechazo (a inversiones universalmente conflictivas en áreas como la pornografía, el tráfico de drogas), del principio de temática controversial (sobre inversiones conflictivas para grupos determinados: energía nuclear, comercio de armas), del principio de prudencia (que opera sobre los resultados en el medio ambiente o en las personas de determinadas compañías) $\mathrm{y}$ del principio de negligencia (que funciona internamente con los managers de estos fondos en tanto indica que deben poner atención en las consecuencias de sus decisiones de inversión y excluir la ignorancia como excusa) (Joly 1993). Como 
criterios positivos para la inversión aparecen la igualdad de oportunidades, la transparencia en la información, el compromiso solidario con la sociedad, la seguridad en el trabajo y el apoyo al entrenamiento y la educación entre otros (Muñoz-Torres et al. 2004).

Mecanismos y regulaciones transnacionales también han aparecido en la última década en este campo: iniciativas como el Global Compact on Social Responsability promovido por las Naciones Unidas (2000), las directivas para compañías multinacionales de la OECD (1999), la Declaración Tripartita de la ILO sobre compañías internacionales y política social (1977-2000), el estándar AA-1000 creado en 1999 por el Institute of Social Ethical Accountability y la SA-8000 promovida por la agencia de acreditación Council on Economic Priorities. (Muñoz-Torres et al. 2004:206)

A ellas puede unirse el Ethics Compliance Standard (ECS2000) desarrollado en 1999 por el Business Ethics and Compliance Research Center de Reitaku, Japón (Taka 2002) o, más recientemente, las Norms on the Responsibilities of Transnational Corporations and Other Business Enterprises with Regard to Human Rights de las Naciones Unidas (UN 2003).

En todos estos casos el acoplamiento de cooperación y economía viene establecido por una limitación de la contingencia operativa de la economía a base de la complejidad semántica del sistema de la cooperación. Acoplamientos de este tipo son ciertamente débiles dada la robustez y densidad de la autopoiesis de la economía y la baja diferenciación de un sistema de la cooperación. Pero un acoplamiento estructural no requiere especificar todo el campo operativo de los sistemas que se acoplan. Si para determinadas operaciones de la economía regulaciones de este tipo son posibles (sea por las razones justificatorias que sea: mejor imagen de la empresa, expectativa de acceso a más mercados o el bien de la humanidad), eso basta para la formación del acoplamiento y para la concretización de inversiones socialmente responsables. En la economía misma, en todo caso, podrá seguir existiendo tráfico de armas, de drogas o pornografía infantil, pero ese tipo de operaciones, ciertamente, no serán reconocidas como acoplamiento cooperación-economía - a menos que el acoplamiento tenga lugar como lavado de dinero en organizaciones de beneficencia o acciones por el estilo.

(c) El acoplamiento de cooperación y sistema jurídico debe analizarse en dos planos: el de las regulaciones vinculantes de tipo corporativo que operan de modo transnacional y el de los sistemas jurídicos nacionales. La relación de actividades 
de cooperación con la economía y la política por medio de organizaciones supranacionales de cooperación revisada en los apartados anteriores, produce múltiples regulaciones de tipo anacional por medio de las cuales esas organizaciones y organizaciones locales logran un tipo de operación homogéneo en sus rasgos fundamentales. El ECS2000 referido más arriba es un buen ejemplo de ello. A través de él, se busca un procedimiento que no defina objetivos a las organizaciones sino que permita a cada una de ellas establecer los propios criterios legales, éticos y sociales y la forma en que estos serán públicamente informados (Taka 2002).

Sin embargo, donde el acoplamiento puede ser observado con mayor claridad es en las regulaciones de la International Labor Organisation. Como lo ha señalado Peer Zumbansen: "La historia de los intentos de la ILO de crear derechos laborales mundiales para proteger a los trabajadores, ya había comenzado a fines del siglo XIX. De hecho, la propia creación de la ILO da un fuerte testimonio del compromiso institucional y de su conducción hacia la cooperación internacional" (2005:21). El desarrollo más reciente de las regulaciones de la ILO está marcado por la Declaration of the Fundamental Principles and Rights at Work de 1998. La declaración contempla cuatro principios: libertad de asociación y negociación, protección contra el trabajo forzado, eliminación del trabajo infantil y de cualquier forma de discriminación (ILO 2006). Según Zumbansen, "a través de la Declaración de 1998, la ILO ha instalado un programa multipartito de monitoreo y cooperación que espera crear un poderoso programa de nueva solidaridad con una dimensión práctica efectiva: los países trabajarán cercanamente al importar una convención al derecho doméstico" (2005:34).

Como en el caso del acoplamiento de cooperación y economía, la relación de cooperación y derecho no predefine las operaciones internas del sistema jurídico, pero sí especifica un horizonte de contingencia a base de principios semánticamente definidos en el sistema de la cooperación. Los principios deben traducirse en normas jurídicas para ser jurídicamente vinculantes en el plano nacional. Esto no es simple, pero cuando eso sucede, tiene lugar la digitalización de operaciones en dos sistemas funcionales que supone el acoplamiento estructural: el derecho opera según normas jurídicamente definidas en materias laborales que desde el sistema de la cooperación se observarán coherentes con los principios de su propio orden semántico.

Probablemente en ello radique la principal dificultad de concretización de la idea de derechos humanos en forma de decisiones jurídicamente válidas. La semántica de los derechos humanos es contingencia comunicativa de la diferenciación de la cooperación que se autoindica a través de la idea de derechos cosmopolitas como horizonte vinculante moral de la humanidad. Para el sistema de la cooperación este tipo de semánticas contribuye a la designación de un campo problemático 
que llama la atención de las operaciones sistémicas hacia temáticas particulares especificadas en los propios derechos y que el sistema entonces puede tematizar como exclusión.

Todo esto, sin embargo, no alcanza a ser sistema jurídico, aun cuando intentos tibios de vinculación puedan tener lugar, como lo ha expresado Habermas:

En caso necesario, la Comisión de Derechos Humanos de la ONU tiene la potestad de ejercer su influencia diplomática sobre los gobiernos correspondientes. Examina también las peticiones de ciudadanos particulares contra las violaciones de derechos cometidas por sus gobiernos. Aunque hasta ahora no han tenido gran importancia práctica, estas quejas individuales son una institución de importancia fundamental, porque con ellas los ciudadanos individuales son reconocidos como sujetos inmediatos del derecho internacional. (2006:158)

El problema central para el acoplamiento de la semántica de los derechos humanos con operaciones jurídicas radica nuevamente en la gramática transformacional de derechos morales (semántica de una solidaridad transnacional de tipo cosmopolita) en derechos jurídicamente exigibles. La creación del Tribunal Penal Internacional así como la Corte Europea de Derechos Humanos o la Comisión Interamericana de Derechos Humanos constituyen pasos adelante en este sentido. Ellas permiten tender un puente que traduce en términos jurídicos la complejidad moral de derechos de tipo cosmopolita que están a la base de un sistema global de cooperación.

Cada una de estas formas de acoplamiento estructural contribuye y a la vez es efecto de la creciente diferenciación del sistema de la cooperación. El carácter autorregulado y autoorganizado de este sistema se constata en la densificación de sus estructuras y en la progresiva consolidación de su semántica durante el siglo XX. Ciertamente, la intensificación y expansión en el siglo XXI de estos acoplamientos con los sistemas analizados, así como con la religión a través de una actualización de la doctrina social, con la educación por medio del reforzamiento de la idea de educación para todos, con la ciencia a través de la orientación a la utilidad social del conocimiento científico o con los medios de comunicación por medio de fórmulas de publicidad solidaria, pueden conducir al sistema a un empleo con mayor celeridad de su medio simbólico, es decir, a transferir la libertad de inclusión ganada en nuevas acciones colaborativas y a la consolidación de su función de transformación de la exclusión en inclusión. Esto es condición de la autopoiesis del sistema. Mientras ello no suceda el sistema no logrará asegurar la reproducción temporalmente continua de lo específico de su comunicación. Pero este es un problema evolutivo que sólo la evolución puede resolver. 


\section{Referencias bibliográficas}

Arnold, Marcelo y Daniela Thumala, 2006. "Colaboración, participación y sociedad civil en Chile: reflexión para la acción.” Persona y Sociedad, Vol. XX, № 1, 143-156.

Bock, Kenneth, 2001. “Teorías del progreso, el desarrollo y la evolución.” En: Tom Bottomore y Robert Nisbet, comps. Historia del análisis sociológico. Buenos Aires: Amorrortu, 59-104.

Brunkhorst, Hauke, 2002. Solidarität. Von der Bürgerfreundschaft zur globalen Rechtsgenossenschaft. Frankfurt: Suhrkamp.

Dockendorff, Cecilia, 1995. Solidaridad: la construcción social de un anhelo. Santiago: UNICEF.

Durkheim, Emile, 1985 [1893]. La división del trabajo social. Barcelona: Planeta-Agostini.

Felix, Joseph, 1880. Cristianismo y socialismo. O el remedio al mal social por la caridad cristiana. Madrid: Agustín Jubera.

Friedrich, Carl Joachim, 2004. La filosofía del derecho. México DF: Fondo de Cultura Económica.

Habermas, Jürgen, 1988. Theorie des kommunikativen Handelns. Frankfurt: Suhrkamp. ,2000. Facticidad y validez. Madrid: Trotta. 2006. El Occidente escindido. Madrid: Trotta.

Hagen, Roar, 2000. "Rational solidarity and functional differentiation." Acta Sociológica, Vol. 43, 27-42.

Heidenreich, Martin, 2005. "Subsidiarität und Solidarität im nationalen und europäischen Rahmen.” Disponible en: http://web.uni-bamberg.de/sowi/europastudien/dokumente [junio 2006].

Herweg, Vera, 2005. Im Schatten von Staat und Marka: Idee und Praxis der Gemeinwirtschaft in Deutschland und Brasilien. Tesis (PhD), Philosophische Fakultät der Westfälischen Wilhelms-Universität.

ILO, 2006. "Declaration of the Fundamental Principles and Rights at Work." Disponible en: www.ilo.org/dyn/declaris/declarationweb.indexpage

Jannet, Claudio, 1892. "French catholics and the social question." Quarterly Journal of Economics, October, 137-161.

Joly, Carlos, 1993. "Ethical demands and requirements in investment management." Business Ethics: A European Review, Vol. 2, N 4, 171-177.

Kaen, David, 1999. "Diversity, solidarity and civic friendship." The Journal of Political Philosophie, Vol. 7, Number 3, 267-286.

Kallscheuer, Otto, 2001. "Solidarität — aus politischer Sicht." SKZ, 46, 11-19.

Lechner, Norbert, 1999. "El estado en el contexto de la modernidad." En: Norbert Lechner, René Millán, Francisco Valdés Ugalde, eds. Reforma del estado y coordinación social. México DF: Plaza y Valdés Editores, 39-54. 
Luhmann, Niklas, 1971. "Systemtheoretische Argumentationen. Eine Entgegnung auf Jürgen Habermas.” En: Jürgen Habermas y Niklas Luhmann. Theorie der Gesellschaft oder Sozialtechnologie. Frankfurt: Suhrkamp, 291-405.

, 1985. El amor como pasión. La codificación de la intimidad. Barcelona: Península. 1990a. "The world society as a social system." En: Niklas Luhmann. Essays on Self-Reference. New York: Columbia University Press, 175-190.

, 1990b. "The state of the political system." En: Niklas Luhmann. Essays on SelfReference. New York: Columbia University Press, 165-174.

1991. "Erleben und Handeln." Soziologische Aufklärung 3. Opladen: Westdeutscher Verlag, 67-80.

1997a. Die Gesellschaft der Gesellschaft. Frankfurt: Suhrkamp.

1997b. Das Recht der Gesellschaft. Frankfurt: Suhrkamp.

, 1998a. "Inclusión y exclusión.” En: Niklas Luhmann. Complejidad y modernidad. Madrid: Trotta, 167-195.

, 1998b. "Los medios generalizados y el problema de la contingencia." Teoría de los sistemas sociales (artículos). México DF: Universidad Iberoamericana, 9-73.

1998c. "Consideraciones introductorias a una teoría de los medios de comunicación simbólicamente generalizados." Complejidad y modernidad. Madrid: Trotta, 99-130.

2000. Vertrauen. Stuttgart: Lucius \& Lucius Verlagsgesellschaft.

2002. El derecho de la sociedad. México DF: Universidad Iberoamericana.

Luhmann, Niklas y Rafaelle Di Giorgi, 1998. Teoría de la sociedad. México DF: Universidad Iberoamericana, Triana.

Luhmann, Niklas y Karl Eberhard Schorr, 1993. El sistema educativo. México DF: Universidad de Guadalajara, Universidad Iberoamericana, Instituto Tecnológico y de Estudios Superiores de Occidente.

Mascareño, Aldo, 2006. "Ética de la contingencia por medio del derecho reflexivo." En: Artur Stamford, ed. Sociología do Direito. A prática da teoría sociologica. Pernambuco: Lumen Juris.

Mena, Ricardo, 2005. La diferenciación de la solidaridad. Tesis (Lic.), Departamento de Ciencias Sociales, Universidad Alberto Hurtado.

Meyer-Bisch, Patrice, 2000. "De una sucesión de generaciones a un sistema de los derechos humanos.” Persona y Sociedad, Vol. XIV, Nº 1, 123-132.

Muñoz-Torres, María Jesús, María Ángeles Fernández-Izquierdo, María Rosario BalaguerFranch, 2004. "The social responsibility performance of ethical and solidarity funds: an approach to the case of Spain." Bussiness Ethics: A European Review, Vol. 13, № 2/3, 200-218.

Münker, Hans, 2001. “Überleben ohne Solidarität?” Disponible en: http://web.uni-marburg.de/isem/WS01_02/docs/soli.pdf [junio 2006]. 
Nederman, Cary, 1987. "Sovereignty, war and the corporation: Hegel on the medieval foundations of the modern state." Journal of Politics, Vol. 49, Issue 2, 500-554.

OECD, 2006a. "About OECD”. Disponible en: www.oecd.org/about [junio 2006]. 2006b. 2005 Development Co-Operation Report, Vol. 7, N 1, OECD.

Parsons, Talcott, 1966. El sistema social. Madrid: Revista de Occidente.

Rawls, John, 2002. La justicia como equidad. Una reformulación. Barcelona: Paidós.

Razeto, Luis, 1993. Los caminos de la economía de la solidaridad. Santiago: Vivarium.

Rodríguez, Darío, 2004. Organizaciones para la modernización. México DF: Universidad Iberoamericana.

Roos, Lothar, 2004. Die Katholische Soziallehre und die Reform des Sozialstaates. Köln: Bund Katholischer Unternehmer e.V.

Rorty, Richard, 1996. Contingencia, ironía y solidaridad. Barcelona: Paidós.

Rousseau, Jean-Jacques, 1992 [1762]. El contrato social. Madrid: Edaf.

Simpson, Brad, 2004. "Solidarity in an age of globalization: The transnational movement for East Timor and U.S. Foreign Policy.” Peace \& Change, Vol. 29, № 3 \& 4, 453-482. Spencer-Brown, George, 1979. Laws of Form. New York: E.P. Dutton.

Stichweh, Rudolf, 2000. Die Weltgesellschaft. Soziologische Analysen. Frankfurt: Suhrkamp. , 2004. "Der Zusammenhalt der Weltgesellschaft. Nicht-normative Integrationstheorien in der Soziologie." Working Papers Institut für Weltgesellschaft, No 6.

Taka, Iwao, 2002. "CRS and the Ethics Compliance Standard (ECS2000) in Japan.” En: Corporate Social Responsibility. Concepts and Solutions. Copolco Workshop.

Teubner, Günther, 1993. Law as an Autopoietic System. Oxford: Blackwell.

Tönnies, Ferdinand, 1991 [1878]. Gemeinschaft und Gesellschaft. Grundbegriffe der reinen Soziologie. Darmstadt: Wissenschaftliche Buchgesellschaft.

United Nations, 2003. "Norms on the Responsibilities of Transnational Corporations and

Other Business Enterprises with Regard to Human Rights.” En: U.N. Doc. E/CN.4/ Sub.2/2003/12/Rev.2.

Willke, Helmut, 1987. "Kontextsteuerung durch Recht? Zur Steuerungsfunktion des Rechts in polyzentrischer Gesellschaft." En: Manfred Glagow y Helmut Willke, eds. Dezentrale Gesellschaftssteuerung. Probleme der Integration polyzentrischer Gesellschaft. Pfaffenweiler: Centauros-Verlagsgesellschaft, 3-26. , 1996a. Systemtheorie I: Grundlagen. Stuttgart: UTB. 1996b. Ironie des Staates. Frankfurt: Suhrkamp.

Zulueta, Sebastián, 2004. La evolución del voluntariado en Chile entre los años 1990 y 2002. Tesis (Mg.) Instituto de Sociología, Pontificia Universidad Católica de Chile.

Zumbansen, Peer, 2005. "The transnational law of corporate governance and labor rights." CLPE Research Paper, Vol. 1, № 2. 